\title{
"A viagem de volta": o reconhecimento de indígenas no sul do Brasil como um evento crítico
}

\author{
Ceres Víctora \\ Doutora em Antropologia (Brunel University) \\ Professora na Universidade Federal do Rio Grande do Sul \\ ceres@victora.com.br
}

\begin{abstract}
Resumo O presente artigo enfoca a problemática do reconhecimento étnico de indígenas por parte do Estado, sugerindo que este pode ser pensado como um evento crítico, no sentido de que transforma percepções, ações e relações entre diferentes agentes envolvidos nos processos de territorialização, além de possibilitar a construção de memórias que tecerão discursos e narrativas específicos. A partir de uma pesquisa etnográfica realizada junto à comunidade Charrua da Aldeia Polidoro de Porto Alegre (Brasil), abordo inicialmente a historiografia dos índios Charrua do Uruguai que ressalta fundamentalmente a extinção da etnia, contrapondo a isso as suas narrativas que assumem a ótica da sobrevivência, condição de possibilidade para seu reconhecimento no Brasil atual. Na sequência apresento situações e discursos que considero reveladores da conflituosa relação deles com alguns agentes públicos que se veem confrontados com a agenda e a agência políticas desse "novo" povo indígena. Por fim, sugiro que, em parte, esses conflitos estão relacionados a diferentes formas de experienciar o tempo. Para os indígenas, por um lado, a construção narrativa que lhes dá possibilidade de se reconhecerem e serem reconhecidos como tais implica a corporificação da interprenetação dos tempos passado e presente e, nesse sentido, sua espera pela promoção de seus direitos constitucionais é contabilizada desde tempos muito remotos. Por outro lado, para os agentes públicos, o reconhecimento étnico oficial é um ponto específico no presente, a partir do qual estes iniciam um processo lento e gradual de reconhecimento da condição de indígenas, dentro do "tempo da burocracia" no qual estão imersos cotidianamente.
\end{abstract}

Palavras-chave: evento crítico; construção narrativa; reconhecimento étnico; populações indígenas; tempo.

My journey is not one about of going forward, but rather of turning back, about collecting words and thoughts that I think as having forged connections between me and my interlocutors in the field.

(Veena Das)

\section{Introdução}

$\mathrm{O}$

PRESENTE ARTIGO ENFOCA a problemática do reconhecimento étnico de indígenas por parte do Estado, sugerindo que este pode ser pensado como um evento crítico, uma vez que transforma percepções, ações e relações entre diferentes agentes envolvidos nos processos de territorialização, além de possibilitar a construção de memórias que 
tecerão discursos e narrativas específicos. Porém, para que esta argumentação se apresente de forma consistente, faz-se necessária uma muito breve incursão por outros temas, tais como:

(1) o debate sobre a questão da territorialização de indígenas na atualidade;

(2) o relato de algumas histórias e experiências de um grupo específico que será alvo de análise neste artigo;

(3) os dilemas do pleito pelo reconhecimento étnico, conforme descrição dos participantes da pesquisa;

e (4) a apresentação de um caso relacionado à problemática da saúde como exemplo das animosidades na relação dos indígenas com as instituições públicas.

Com isso, os diferentes segmentos deste artigo pretendem construir a proposta de pensar o reconhecimento étnico oficial do Estado como um evento crítico complexo e multifacetado, que ocorre em temporalidades diferentes para os agentes sociais envolvidos nesse processo. Sem intenção de chegar a uma conclusão que tenha validade para outros casos, este artigo pretende ser um espaço de reflexão na busca de elementos teórico-metodológicos para compreender antropologicamente as complexidades da relação de indígenas recentemente reconhecidos com as instituições do Estado brasileiro.

\section{Sobre indígenas e processos de territorialização}

Nas últimas duas décadas observou-se no Brasil um aumento importante no número de grupos ou comunidades que obtiveram reconhecimento estatal como povos indígenas brasileiros, após um longo período histórico de uma aparente invisibilidade. Antropólogos indigenistas estimam que mais de cinquenta grupos, do norte ao sul do Brasil, têm demandado reconhecimento nas últimas décadas (Arruti, 2011; French, 2004), e se reorganizado no sentido do que Oliveira (1998) tem chamado de "processo de territorialização":

[...] movimento pelo qual um objeto políticoadministrativo - nas colônias francesas seria a "etnia", na América espanhola as "reducciones" e "resguardos", no Brasil as "comunidades indígenas" vem a se transformar em uma coletividade organizada, formulando uma identidade própria, instituindo mecanismos de tomada de decisão e de representação, e reestruturando as suas formas culturais (inclusive as que o relacionam com o meio ambiente e com o universo religioso). (Oliveira,1998, p.56)

Trata-se, portanto, de uma transformação que não só aciona elementos simbólicos e práticos e inaugura, por assim dizer, uma nova etapa na vida das pessoas diretamente envolvidas - no caso os indígenas -, mas também provoca um reposicionamento de uma série de outros agentes sociais e políticos. Os processos de territorialização não são exclusivos do período mais recente da nossa história. Ainda assim, observa-se que leis e disposições favoráveis à proteção e promoção dos povos indígenas no Brasil, presentes na Constituição de 1988 (Brasil, 1988), juntamente com o disposto na Convenção 169 de Organização Internacional do Trabalho da Organização da Nações Unidas (OIT Brasil, 2011), que indica o direito ao autorreconhecimento das comunidades, vieram favorecer esse movimento e possibilitar uma mudança na maneira com que certos grupos passaram a se reconhecer e a serem reconhecidos dentro da sociedade brasileira. Além disso, ou talvez por causa disso, abriu-se também a possibilidade para esses grupos participarem das políticas e instituições públicas a partir desse outro lugar social, encaminhando reivindicações de direitos garantidos pela Constituição.

A possibilidade de integrar-se como indígena e as implicações legais do processo de autoidentificação e de reconhecimento estatal de grupos nesse momento histórico e político do país têm sido avaliadas de formas diversas entre setores da sociedade, como a mídia, a Academia, o empresariado, os políticos, as organizações religiosas, as organizações de defesa dos Direitos Humanos. Em um polo, aparecem os que defendem o inquestionável direito ao autorreconhecimento dos povos indígenas e a necessidade de reparação da dívida histórica que o Brasil tem com seus antepassados. Em outro extremo, há os que sugerem que a assimilação de aborígines a sociedades colonizadas é um processo histórico inevitável, irreversível e mesmo desejável e, assim sendo, não requer reparação. Um exemplo desse último pode ser encontrado no artigo "A farra da antropologia oportunista" publicado na revista Veja (Coutinho, Paulin \& Medeiros, 2010).

O reconhecimento étnico se apresenta, assim, como um evento que mobiliza, desde questões de Direitos Humanos, até decisões sobre a utilização de recursos do Tesouro Nacional. Isso porque o direito a esse reconhecimento, estando associado aos direitos constitucionais, abre uma série de possibilidades aos grupos indígenas reconhecidos, tais como: o direito de demarcação ou aquisição de terras; o direito de usufruírem de condições sanitárias e de saúde para sobrevivência não apenas individual, mas da etnia; o direito à educação, tendo assegurada a utilização das suas línguas nas escolas; o direito à atenção à saúde, 
contemplando a diversidade. Tudo isso mobiliza interesses e recursos públicos e privados, às vezes de difícil conciliação (Silva, 2008).

Isso não significa dizer que os grupos que passam a ser reconhecidos oficialmente pelo Estado obtenham de fato os seus direitos constitucionais logo após o ato. Processos como o de demarcação de terras indígenas e de investimento em melhorias nas condições de vida, saúde e educação têm se mostrado muito mais complicados, burocráticos e demorados do que se possa imaginar. Contudo, esse reconhecimento étnico oficial aciona uma cadeia de ações e reações por parte de agentes sociais e instituições políticas que irão se confrontar com o surgimento desse novo agente político, a saber, o indígena com direitos específicos. Observa-se que, mesmo órgãos públicos que já têm como atribuição lidar com as implicações diretas do reconhecimento ético de grupos indígenas, como a Fundação Nacional do Índio (Funai) e a Fundação Nacional de Saúde (Funasa), a quem cabia, na época do desenvolvimento desta pesquisa, a execução de ações de saneamento e de promoção da saúde em comunidades indígenas se enredam em uma teia burocrática e levam, junto com eles, os indígenas que ingressam em processos de territorialização com expectativa de verem suas vidas melhoradas em um curto espaço de tempo. ${ }^{1}$

Essas observações iniciais me levaram a uma série de perguntas: o que significa tornar-se oficialmente indígena? Como se processa a transformação de indígenas não reconhecidos em agentes políticos capazes de reivindicar direitos que não se colocavam anteriormente para eles? Como são reconstituídas as lembranças individuais no sentido da construção de uma memória coletiva indígena que faça sentido para si e para os outros? Como se dá a formação de subjetividades perante o novo espaço político com o repertório de experiências pregressas?

Com relação às instituições envolvidas nos processos de territorialização, pergunto sobre as repercussões do processo de reconhecimento étnico de um grupo: como os direitos constitucionais são incorporados e transformados em ações pelos agentes públicos? Quais discursos são acionados no contato com indígenas empoderados pelo reconhecimento oficial?

Estas são algumas das questões que foram adquirindo sentido no transcorrer da pesquisa etnográfica que tenho realizado entre indígenas que vivem na cidade de Porto Alegre, mais precisamente entre dois coletivos, um Kaingang e outro Charrua. Aproximei-me deles por conta de um projeto maior que tem como referência a Antropologia da Saúde. Mes- mo sem me propor a respondê-las neste momento, entendo que precisam ser explicitadas, uma vez que elas me instigaram a refletir sobre o reconhecimento étnico-estatal de grupos indígenas, tendo como horizonte teórico-metodológico a abordagem de eventos críticos.

Os eventos críticos têm sido muitas vezes associados a acontecimentos de grande magnitude a partir dos quais os dramas pessoais e coletivos se misturam com transformações políticas, sociais e morais e tecem, pelo caminho, um conjunto de deslocamentos com implicações na ordem do cotidiano (Das, 1999 e 2007; Silva, 1998 e 2010). No entanto, os eventos críticos também podem ser pensados em relação a situações mais restritas no sentido quantitativo, mas igualmente enfocam dramas que envolvem transformações na vida individual ou de pequenos grupos, provocando redefinições de categorias de reconhecimento do mundo, formas de entendimento e de subjetificação (Das, 1999).

É nesse sentido que estou sugerindo essa abordagem para compreender o reconhecimento étnico daqueles indígenas que fazem a "viagem de volta" (Oliveira, 1998, p. 65). O termo "viagem de volta", que pego emprestado de Oliveira, se apresentou inicialmente para mim como uma forma de evitar outras expressões como, por exemplo, "etnogênese", "novas etnias", ou "índios emergentes". Tais termos sugerem uma ruptura total entre as possíveis histórias pregressas desses grupos e a (re)organização atual das suas vidas, o que seria insustentável ante o pressuposto de que as memórias coletivas nunca surgiram de um ponto zero, mas podem se reestruturar a partir de novas reordenações do mundo no qual pessoas/grupos vivem atualmente. Ainda: outra dimensão da ideia de "viagem de volta" que me pareceu interessante é a que está expressa na epígrafe deste artigo (Das, 2007, p. 1) e que conforma também a orientação teórico-metodológica desta pesquisa, ou seja, a tentativa de retornar, a partir de narrativas atuais, a pontos da trajetória de um grupo indígena, tecendo nas conversas com eles a sua atual situação social e política. Além disso, como pretendo deixar claro mais adiante nessa exposição, a "viagem de volta" se tornou uma chave interpretativa para compreender o processo de interpenetração dos tempos passado e presente, fundamentais para a significação do reconhecimento étnico como um evento crítico. Estou sugerindo, com isso, que esse reconhecimento por parte do Estado promove, entre outras coisas, uma reorganização da memória coletiva de modo a fazer sentido à vida dos indígenas, agora como agentes políticos reconhecidos

1. Importante ressaltar aqui que os órgãos governamentais que têm atuação sobre a saúde indígena encontram-se nesse momento em fase de reformulação. Algumas atribuições da Funasa passaram, a partir da segunda metade do ano de 2010, para a Funai, em um processo de redistribuição de tarefas, em uma mudança ainda recente e de difícil avaliação. 
pelo Estado, os quais, nesse processo de reconstrução, mobilizam uma série de elementos de identificação cultural.

No presente artigo, vou enfocar especificamente a história da comunidade Charrua, que vive atualmente na Aldeia Polidoro, em Porto Alegre, e o que entendo que seja o seu percurso rumo à "viagem de volta". Para tanto, vou abordar a historiografia dos índios Charrua do Uruguai e a sua suposta extinção. Em contraponto a isso, apresento as narrativas de persistência dos Charrua de Porto Alegre na "viagem de vinda", por assim dizer, do interior (região da Missões) para a capital gaúcha (Porto Alegre), até iniciarem a "viagem de volta", que tem como causa e consequência o seu reconhecimento étnico oficial no Brasil na atualidade. $\mathrm{Na}$ sequência, introduzirei situações e discursos que considero reveladores da sua conflituosa relação com alguns agentes públicos que se veem confrontados com a agenda e agência políticas desse "novo" povo indígena. Por fim, vou sugerir que, em parte, esses conflitos estão relacionados a esse evento crítico que é vivido de forma diferente pelos indígenas e pelos agentes públicos, na medida em que suas formas de experienciar o tempo também são diversas. Para os indígenas, por um lado, a construção narrativa que lhes dá possibilidade de se reconhecerem e de serem reconhecidos como tais implica na corporificação dos tempos passado e presente. Nesse sentido, sua espera pela promoção de direitos constitucionais é contabilizada desde um tempo distante. Por outro lado, para os agentes públicos, o reconhecimento étnico oficial ocorre em um ponto específico do presente, a partir do qual eles iniciam um lento e gradual processo de assimilação daquela condição, dentro do "tempo da burocracia" em que vivem cotidianamente.

O trabalho realizado junto aos Charrua teve a pretensão de se transformar numa etnografia da experiência desses indígenas. Essa perspectiva pretende atentar em especial para aquilo que está vitalmente em jogo para grupos e indivíduos (Kleinman \& Kleinman, 1991; Bruner, 1986a e 1986b). Assim sendo, os sujeitos da pesquisa devem ser tomados como interlocutores, e suas perspectivas e vozes devem ocupar de forma abrangente o espaço etnográfico. Essa perspectiva tem sido empregada em pesquisas na área da Antropologia da Saúde que, mesmo sem ter necessariamente como referência eventos críticos específicos, enfocam também as dimensões de dor, violência e sofrimento da experiência social de grupos e indivíduos (Fassin, 2007; Bihel, 2006; Das et al., 2000 e 2001; Kleinman, Das \& Lock, 1997).
A nossa ${ }^{2}$ aproximação inicial com os Charrua da Aldeia Polidoro se deu a partir de um encontro informal com o grupo em local público, quando fomos requisitados a ajudá-los na construção das casas da Aldeia. Segundo seus depoimentos, fazia três anos que o processo encontrava-se estagnado por falta dos pré-requisitos exigidos para que o financiamento recebido do Governo Federal fosse liberado pela Caixa Econômica Federal. Um convívio intenso se estabeleceu ao longo de um período de um ano e dois meses (a partir de maio de 2009) e proporcionou rumos inesperados ao acompanharmos muito mais do que o processo de liberação do referido financiamento, mas nos envolvendo em muitas outras esferas das suas vidas. Adquirimos, assim, proximidade suficiente que nos permitiue enfocar a experiência cotidiana deles junto aos agentes públicos de quem eles se aproximavam para reclamar seus direitos.

A principal interlocutora nesta pesquisa é Acuab, a líder do grupo, a cacique-geral do Povo Charrua do Rio Grande do Sul, na condição de porta-voz do grupo, embora o trabalho de campo tenha envolvido praticamente todos os membros da comunidade, adultos e crianças, cujas vozes também foram ouvidas $\mathrm{e}$, em alguns casos, transcritas neste artigo. O registro dos relatos, entrevistas e reuniões de que participei foi feito através de gravador de som e filmagens, todos com a anuência e autorização da comunidade, para quem foi fornecido também cópia de todo o material bruto da pesquisa.

\section{A história dos Charrua sob a ótica da sobrevivência}

A historiografia dos povos nativos do sul da América do Sul refere aos indígenas da etnia Charrua como um grupo nômade que vivia no Uruguai, em partes da Argentina e no extremo sul do Brasil. Esse grupo sofreu um intenso processo de etnocídio desde a chegada dos espanhóis (Silva, 2008). Uma persistente assimilação à sociedade colonizada, juntamente com um acontecimento dramático que ficou conhecido como a Batalha de Salsipuedes, teria sido responsável pelo seu desaparecimento na década de 1830 (Picerno, 2009). Essa referência à historiografia é importante porque, segundo o grupo autodeclarado e oficialmente reconhecido como Charrua que vive hoje em Porto Alegre, foi a mobilidade que permitiu a sobre- 
vivência de membros do grupo, contrariando assim a versão historiográfica sobre o extermínio do povo. Alguns relatos feitos ao longo do trabalho de campo fizeram referência à trajetória de deslocamentos de um grupo de pessoas, referidas por Acuab genericamente como seus antepassados, em um período da história do sul da América do Sul particularmente marcado por conflitos com espanhóis no Uruguai. A cacique do grupo referiu-se certa vez à execução dos Charrua do Uruguai pelos "espanhóis" e ao seu suposto extermínio da seguinte maneira: "bobos são os que foram na reunião [em Salsipuedes]. Os Charrua espertos são os meus avós que fugiram". Dessa forma, ela reforça a interconexão dos tempos passado e presente, deslocando a história contada a partir da ótica do extermínio para a da sobrevivência. A líder do grupo, em diferentes ocasiões, chamou a atenção para o que seriam as evidências da sua origem étnica. Juntou as histórias que ouviu sobre seus "antepassados", apresentou itens de cultura material, ${ }^{3}$ os segredos sobre o idioma, o conhecimento e a prática xamânica sobre ervas medicinais, comidas e bebidas rituais, entre tantas outras práticas aparentemente menos relevantes para sua identificação com a condição de indígena da etnia Charrua que havia aprendido com seus pais.

Entre as práticas destacam-se as técnicas de sobrevivência para as quais Acuab e seus irmãos foram treinados - "desde muito bebezinhos, muito pequenininhos, como correr e subir as árvores"- para escaparem das constantes perseguições e ameaças que sofriam no interior do Rio Grande do Sul, quando moravam "no mato". As ameaças, inclusive de morte, algumas narradas com muitos detalhes, são apresentadas como o principal motivo pelo qual sua família teria vindo gradativamente para cidades maiores até chegarem a Porto Alegre, onde viveram por quarenta anos em uma vila habitada por classes populares, antes de iniciarem o processo de pedido de reconhecimento étnico:

Quando nós saímos, eu e meus pais Charrua, da oca das Missões, nós viemos conhecer, por um motivo que os fazendeiros correram com nós com uma arma comprida, mais outros paus e mais outros negócios que eles tinham. Correram nós de várias e várias ocas que a gente fazia no mato. Tinha que abandonar tudo, só fugir entre nós. Aí nós fugimos pra cidade de Santo Ângelo. Assim, eu vou contar a história, vou contar um pedacinho da história.

Não devemos assumir que a mudança do grupo de Acuab para cidades maiores e mesmo seu reconhecimento como povo indígena tenha sido um pro- cesso linear evolutivo desde os enfrentamentos com fazendeiros na zona rural para a tranquilidade de um futuro melhor na cidade grande. Um processo complexo de idas e vindas de membros da família é apresentado por Acuab em narrativas entrecortadas pela emoção, causadas por lembranças mobilizadoras de sentimentos de dor e de pesar, como se pode observar no trecho a seguir:

[Foi] quando esse mesmo irmão que conheceu a cidade primeiro, de Santo Ângelo me trouxe para Porto Alegre. Daí depois, eu fui [de volta] pra Santo Ângelo - na época da Maria Fumaça, de trem Maria Fumaça. Eu fui pra Santo Ângelo e disse pra mãe: "Mãe, odeio Porto Alegre; odeio Santo Ângelo; não podemos voltar pra trás porque tamos ameaçados de morte.... Eu vou para Porto Alegre”. Daí minha mãe disse assim: "Me espera mais um dias pra secar a minha roupa". E aí viemos, dormindo pela... com bastante sacos. Eu não sei se alguém, alguma vez viu, ou falou, [mas] nós somos os Charrua que tavam dormindo em Porto Alegre, com sacos, com bastante crianças, bastante gente dormindo pela estrada. Assim, [o que] eu tô falando [é] estrada daqui do centro, as ruas, nós dormia ali. Depois nós fomos conhecer o Morro da Cruz [...].

Dessa maneira, a líder Charrua vai tecendo, através de imagens vivas de um tempo passado, "na época da Maria Fumaça", o processo de deslocamento do seu grupo até a capital. A decisão de vir para Porto Alegre se deu, como se pode observar, pela falta de outras opções melhores. Se ela "odeia Porto Alegre", “odeia Santo Ângelo" e "não pode voltar pra trás", isso indica que a mudança implicou um recurso de sobrevivência. Talvez, de forma semelhante aos seus antepassados, a família tenha mudado para lugares que lhes oferecesse a possibilidade de continuarem vivos.

No entanto, a vinda para Porto Alegre, mais especificamente para o Morro da Cruz, onde a família foi morar, fica marcada tanto por sua duração - quarenta anos - como pelos desafios, dentre os quais a adaptação aos modos de viver em uma vila de classes populares na cidade grande. Segundo Acuab,

ficamos 40 anos no Morro da Cruz, no meio da periferia, do "bang-bang". Era o verdadeiro, ou pior, do que "bang-bang" porque [era] "bang-bang" [que] se juntava. Se fosse em consideração, seria o "bangbang", que seria a linha duma vila do Morro da Cruz quando começava a se tirotear. Mas não, é diferente, é pior do que "bang-bang" porque se juntava a Tuca, se juntava a Coreia, se juntava o Morro da Cruz, e

3. Trata-se nesse caso de "roupas antigas", "rochas lascadas", "bolas de boleadeiras", entre outros itens indubitavelmente de tradição Charrua guardadas pela família, assim descritas por Leite, 2010. 
se tiroteava. Nós tinha, se tava andando na rua, nós tinha que se atirar no chão, na calçada e ficar bem quieto. Uma das balas quase atingiu a cabeça do Cacique [refere-se aqui ao seu filho que é Cacique da Aldeia] quando ele tinha oito anos no Morro da Cruz, a outra bala passou por cima da minha cabeça.

Acredito que esse relato sobre o período que viveram no Morro da Cruz possa ser entendido como uma expressão da carência das regras claras para eles. Esse bairro da cidade, que se caracteriza pela existência de subgrupos associados a vizinhanças específicas - "a Tuca”, “a Coreia” e "o Morro da Cruz" -, que disputam o domínio de territórios locais, confundem as categorias do bem e do mal, em geral mais bem definidas nos filmes de "bang bang".

É importante observar que esse período de "quarenta" anos é pouco detalhado nos seus relatos, exceto pela referência que fazem frequentemente à extensão do período em que viveram lá e a algumas situações dramáticas que experienciaram como os tiroteios, o falecimento da mãe da Cacique e o desaparecimento de uma irmã em circunstâncias até hoje misteriosas para eles. Também me explicaram uma vez a dificuldade de manter alguns segredos indígenas - como o idioma, as receitas de remédios tradicionais, os rituais - em uma vila popular onde há muita proximidade entre as casas e onde o espaço físico é disputado.

Todos esses relatos de entrecuzamentos de espaços e tempos nas recordações do grupo estão teoricamente inspirados no debate sociológico sobre a construção da memória coletiva, mais particularmente no que diz respeito às sutilezas das lembranças, e apontam para aspectos do presentismo da memória (Eckert \& Rocha, 2005; Rocha \& Eckert, 2000; Das, 1999; Halbwachs, 1992). Nesse sentido, o que estou sugerindo é que a versão da historiografia do Uruguai, centrada no extermínio do povo Charrua, não tem correspondente na memória coletiva desse grupo que assume a ótica da sobrevivência. Essa possibilidade de eles percorrerem o caminho para o reconhecimento será discutida a seguir.

\section{O pleito pelo reconhecimento étnico}

O Estado reconheceu o grupo como Charrua no ano de 2007, com base no laudo antropológico - um documento fundamental nesse processo - realizado pelo arqueólogo Sérgio Leite, do Museu Antropológico do Rio Grande do Sul (Leite, 2008 e 2010). Contudo, o processo de integração aos procedimentos voltados à proteção e promoção dos povos indí- genas (Ministério da Justiça, 2007; Silva, 2008; Leite, 2008) não foi simples, rápido e desburocratizado, o que fica evidente pelas narrativas do grupo e pelos documentos a que tive acesso. $\mathrm{O}$ que estou querendo sugerir, com isso, é que os processos que levam ao reconhecimento étnico são extremamente complexos e fazem vir à tona, em diferentes momentos, posições mais ou menos favoráveis à incorporação de grupos autodeclarados indígenas. Na percepção da comunidade Charrua da Aldeia Polidoro, esses processos são vividos como "batalhas", enfrentadas à base de "lutas”. Nas palavras da Cacique Acuab:

Primeiro foi a luta pelo reconhecimento. Porque, se não lutasse, o reconhecimento não ia vir de mão beijada, não ia bater na porta: luta com sangue. As crianças da Ângela e as da Solange botaram muito sangue; o Osvaldo botava sangue - naquela época que ele tinha sido operado; o Márcio botava sangue como se fosse Q-suco...

Essa recordação do sofrimento que compreendeu, nas suas palavras, a perda de sangue de vários membros da família, seja no sentido literal como figurado, demonstra a dimensão do tamanho do empreendimento que é o pleito pelo reconhecimento. Para eles foi uma mobilização que está para sempre marcada com sangue, um elemento recorrente da sua narrativa, para que nunca seja esquecida. Assim, se houve sofrimento na "viagem de vinda", o mesmo sentido deve ser dado à "viagem de volta", que é narrada através de uma história de "lutas" e adversidades. Igualmente, foi atribuído um profundo sentido de dor e sofrimento ao período transcorrido entre o reconhecimento oficial até a desapropriação da terra para aquisição por parte do município (Diário Oficial de Porto Alegre, 2008) e a posterior mudança para a área onde hoje se situa a Aldeia, em setembro de 2009 (Leite, 2010).

Entre o reconhecimento oficial e a efetiva mudança para a terra indígena, o grupo foi temporariamente assentado em um pavilhão de reciclagem do Departamento Municipal de Limpeza Urbana de Porto Alegre (DMLU), na zona sul da capital. A permanência ali que deveria ser de "três meses" acabou sendo de "três anos". Esse período é descrito sempre como muito difícil, dada a insalubridade do local, como se pode perceber no trecho do relato de Guaimá, filho da cacique:

Nós pegamos aquela virose, o próprio ambiente já era contaminado. Porque se eu fizesse assim no galpão, já tinha uns bichinhos ali que já tava furando a pele da gente....[era um] depósito de lixo. É, tinha de tudo lá na parede. Não dava nem pra se encostar assim na parede pra descansar um pouquinho que eles entravam pra dentro da pele. 
Vale ressaltar que, embora eu esteja enfocando a história específica desse conjunto de pessoas que se define como "parentes" e que obteve o reconhecimento pelo Estado, eles não se imaginam como os únicos Charrua sobreviventes. Há outros membros que eles chamam de "meu povo", sugerindo que sejam aparentados, provavelmente consanguíneos da cacique por parte de seu pai ou da sua mãe, que vivem no interior do Rio Grande do Sul, em cidades da Região da Missões. Em um diálogo comigo, Acuab afirmou:

- Em São Borja eu tenho meu povo Charrua, em São Miguel das Missões [...] tem meu povo Charrua com idioma e com cultura; tenho em Santo Ângelo [...].

- Eles continuam lá?, eu perguntei.

- Continuam no mesmo lugar, mas não tem terra. Tem um quadradinho com uma moloquinha. São Charrua, mas quem dá o reconhecimento é nós mesmos. E como eu sou reconhecida, e sou Cacique Geral, já conversamos com eles.

Esse reconhecimento que é "dado" por eles seria um primeiro passo para que os outros membros do "seu povo" obtivessem também reconhecimento oficial e participassem das políticas de proteção e promoção que o Estado oferece aos grupos indígenas. Entretanto, compreendi também que nem sempre pessoas que talvez pudessem ser reconhecidas oficialmente como indígenas se organizam nesse sentido, por se tratar de um empreendimento de enormes dimensões, que vai envolver, entre outras coisas, a mobilização de lembranças com vistas à construção de uma narrativa focada na condição indígena. Isto não é necessariamente viável para todos, em razão do tempo e das experiências decorridas ao longo da vida.

Um exemplo disso foram algumas tentativas feitas para que outros membros do grupo que Acuab considera como sua família (irmãos da mãe ou do pai e alguns de seus filhos) fossem reconhecidos e, a seu convite, viessem morar na Aldeia Polidoro. Contudo, após alguns meses, estes tiveram a sua identificação revogada por meio judicial, a pedido da própria comunidade original, por não corresponderem à expectativa de como devem se portar indígenas da etnia Charrua. Comportamentos considerados desrespeitosos e perigosos, como o porte de armas de fogo, a utilização de linguagem e músicas de baixo calão ("bagaceiras", nas palavras deles), indícios de práticas religiosas de origem afrobrasileiras, comportamento sexual violento e inadequado, abordagem com fins impróprios das crianças da Aldeia e o uso de bebidas alcoólicas comerciais no cotidiano, fora dos rituais Charruas, foram apenas algumas das práticas condenadas pelo grupo e que os levaram a empreender a remoção desses parentes do local. Segundo Ângela, uma das filhas da cacique, "eles se descaracterizaram como Charrua e a gente em lei [des]reconheceu eles. Então eles não são mais considerados índios Charrua [...] Até porque eles querem viver outro mundo, outra cultura que não batia com a nossa".

Sem me estender mais nessa passagem infeliz da memória da Aldeia Polidoro, desejo apenas salientar que fazer a "viagem de volta" parece requerer acima de tudo um compromisso com certa ordem do mundo que envolva a adesão a valores éticos e morais reconhecidos por eles como característicos dos indígenas Charrua. O reforço dos códigos de pureza e o distanciamento da contaminação representada pelos outros parentes se mostram assim como formas de demonstrar um pertencimento étnico. Isso é colocado à prova por indivíduos, grupos e órgãos públicos - como ocorreu com a Funai, em um primeiro momento -, talvez pelo fato de esses indígenas terem vivido por muitos anos em uma vila de classes populares na situação de pobres urbanos. ${ }^{4}$

\section{O descompasso entre os tempos em relação ao evento crítico}

Neste último segmento vou explorar um exemplo relacionado à saúde indígena para melhor demonstrar uma das complexidades do reconhecimento étnico como um evento crítico. O recurso a esse exemplo está relacionado com os dados que coletei para a pesquisa que, como já referido anteriormente, parte do referencial da Antropologia do Corpo e da Saúde. Trata-se, portanto, da escolha de um caso etnográfico, o que não significa que não existam várias outras dimensões que poderiam ser exploradas sobre as quais eu não me debrucei de maneira tão aprofundada.

\footnotetext{
4. A questão da origem dos indígenas e da legitimidade das suas reivindicações atualmente não é, de forma alguma, específica desse grupo, mas durante o trabalho de campo os Charrua me relataram várias situações nas quais sua identidade indígena foi questionada. Às vezes isso era feito de forma explícita, para seu prejuízo, por pessoas que os abordaram em seus lugares de venda de artesanato após a veiculação do vídeo Os últimos Charrua, episódio da série "Histórias Extraordinárias", exibido pela RBS TV, que mostrava, através de uma dramatização, que os "últimos" haviam morrido na França há quase dois séculos. Nesse caso, segundo eles, algumas pessoas deixaram de comprar seu artesanato, sugerindo que sua identidade não seria verdadeira. Outras vezes, o interesse em reconhecer se a sua origem era verdadeira ou não aparecia de formas mais sutis, como foi o caso de um outro indígena, da etnia Kaingang, que, em conversa informal comigo, comentou que "tirou a sua dúvida" se eles eram mesmo indígenas quando, em uma visita à Aldeia Polidoro, aceitou tomar café. Concluiu ele que a forma de eles prepararem e servirem essa bebida "como índios" Ihe deu a certeza de que eles eram verdadeiros indígenas.
} 
Sabe-se que uma das possibilidades que se abre aos indígenas reconhecidos oficialmente é a inclusão no Subsistema de Saúde Indígena, que tem como um dos princípios a atenção diferenciada à saúde. O que esse conjunto de princípios significa na prática, no entanto, é algo ainda muito debatido, tanto pelos indígenas como por aqueles que tentam se aproximar do tema por interesses acadêmicos (Buchillet, 2007; Langdon, 2007; Langdon \& Diehl, 2007; Langon \& Garrnelo, 2004).

Assim sendo, não é de se surpreender que uma das questões que mais mobilizou os Charrua ao longo do período que convivi com eles foi a reivindicação de melhoria da saúde da comunidade. Isso envolvia, de forma abrangente, desde a instalação da rede de água na comunidade local até outras medidas, como o atendimento médico, preferencialmente a construção de um posto de saúde na Aldeia. Porém, enquanto essas ações eram debatidas junto às "autoridades" (expressão usada por eles para se referirem a qualquer pessoa que julgavam ter algum poder nas instituições onde tinham contato), eles empreendiam muitos outros esforços para obter minimamente o atendimento a doentes, medicamentos, recursos para transporte de pessoas para postos de saúde e hospitais - enfim, cuidados médicos que consideravam essenciais. Isso se precipitou também porque, ao longo dos anos de 2009 e 2010, vários membros da comunidade adoeceram sistematicamente com sintomas de vômito, diarreia, dores no corpo, sangue nas fezes. Esses sintomas eram atribuídos por eles à contaminação da água da Aldeia, que não era tratada. Entretanto, apesar dos inúmeros apelos do grupo à Funasa, em busca de uma solução definitiva, ao Ministério Público Federal e ao Ministério Público Estadual, onde denunciavam semanalmente a falta de atenção daquele órgão federal, muito pouco foi alcançado. Os Ministérios Públicos foram o palco principal, o que indica que eram os locais apropriados para as queixas ao descumprimento da legislação indigenista. Os Charrua pareciam sentir que naqueles espaços tinham o reconhecimento de que seu "sofrimento era real" e onde a "expressão angustiada de vítimas na base da enumeração caso a caso" - seu estilo preferencial de narrativa - era uma evidência que contava (Das, 1999, p.149).

Também me parece relevante apontar o discurso da Funasa, que, se, por um lado, não negava suas atribuições de atuar sobre problemas de saneamento e atenção à saúde dos povos indígenas, por outro, não se comprometia efetivamente com o cumprimento do seu papel. Somente diante das periódicas interpelações dos Ministérios Públicos, a Funasa iniciou no ano de 2010 algumas ações pontuais relativas a questões de saúde, uma vez que não conseguia viabilizar uma equipe de saúde indígena para prestar atenção diferenciada, tampouco a construção de um posto de saúde, medidas consideradas como onerosas ou burocratizadas demais. Algumas vezes ouvi referências ao pequeno tamanho do grupo, que se autocontabilizava como sendo composto por 40 pessoas, mas que os agentes da Funasa insistiam em recontar e questionar, como se o critério quantitativo fosse condição para a obtenção da proteção do Estado.

O que fiquei me perguntando diante dessas dificuldades enfrentadas junto a esses serviços públicos é o que há por trás dos alegados problemas da "burocracia". Este é um termo genericamente usado pelos representantes das instituições para tentar justificar a morosidade dos processos administrativos que poderiam beneficiar a comunidade. Com essa indagação gostaria de retomar a uma das questões apresentadas na introdução deste artigo concernente às formas e aos tempos de assimilação dos processos de territorialização mais recentes por parte das instituições. Vale observar, com relação a esse particular, que a grande maioria dos relatos do grupo envolvia sempre uma contabilização insistente do tempo que haviam esperado por uma solução. Foram "quarenta anos no Morro da Cruz"; foram "três anos" - ao invés dos "três meses" prometidos - no galpão de reciclagem; estavam há "três anos" à espera do financiamento das casas; "duas ou três semanas" que as crianças ficavam doentes e/ou no hospital, entre tantos outros tempos considerados por eles como excessivos. Isso me parece relevante, pois indica que o reconhecimento oficial por parte do Estado, que, na expectativa dos Charrua, se apresentava como uma possibilidade de mudança para melhor em um tempo relativamente rápido, é absorvido pelas instituições de forma muito lenta, período no qual a legitimidade dos indígenas e suas reivindicações parecem ficar em suspenso.

Existe, dessa forma, um descompasso entre o tempo dos indígenas em relação ao tempo dos agentes públicos com os quais eles entram em contato. Nesse sentido, muitas vezes ouvi funcionários das instituições se referirem aos Charrua como "insistentes" demais, "apressados" demais e "agressivos" no exercício da sua agência política. Se pensadas em uma perspectiva temporal, veremos que a insistência é uma função da frequência de reivindicar; a pressa, uma função da urgência das demandas, e a agressividade, um ímpeto derivado de uma espera que, para os Charrua, não deveria mais se prolongar.

Diante de toda essa "insistência" dos indígenas que persistentemente recorriam aos Ministérios Públicos reclamando direitos, no início do ano de 2010, a Funasa começou finalmente a encaminhar algumas das demandas. Uma delas foi a visita de alguns profissionais de saúde à Aldeia, em uma tentativa de resposta à reivindicação de terem uma equipe médica para atender à comunidade. Entretanto os profissionais levados à comunidade foram um fisioterapeuta, 
uma arquiteta e um médico-psiquiatra, para profundo desgosto de todos os membros e da cacique, que questionaram a utilidade dos dois primeiros. Com relação ao terceiro, Acuab avaliou que era uma tentativa de "tampar a boca do povo Charrua [...]. E, tampando a nossa boca com psiquiatra, pra quando eu e meu povo abrir a boca nas autoridades, nos Direitos Humanos, em tudo que é porta, as autoridades mesmo vai dizer: 'nós assinamos um papelzinho e você é louca. Não vamos te ouvir'."

Essas expressões de desconfiança também sugerem, como já referi, que os indígenas não sentem que suas reivindicações são reconhecidas, o que faz aumentar sua sensação de que está havendo uma apropriação do seu sofrimento, nesse caso para a linguagem da doença (Kleinman \& Kleinman, 1991 e 1997).

Outra ação da Funasa foi a negociação de alguns horários preferenciais para atendimento dos indígenas em uma Unidade Básica de Saúde distante vários quilômetros da aldeia. No entanto, ao chegarem lá, eles compartilharam o mesmo tempo e espaço de pessoas não indígenas que esperavam atendimento médico, além de serem hostilizados pelos demais usuários do serviço, que, sem compreender o que estava ocorrendo, desafiavam o direito à prioridade daquele grupo em relação aos demais.

Apenas para finalizar este artigo, retomo à motivação desta escrita que é, entre outras, a de propor que o reconhecimento étnico por parte do Estado pode ser pensado como um evento crítico, no sentido de transformar percepções, ações e relações entre diferentes agentes envolvidos, além de abrir espaço para a construção de memórias que tecerão discursos e narrativas específicas. Entretanto, o exemplo anterior sugere que se trata de um evento crítico que é vivido em temporalidades diferentes por parte dos que fazem a "viagem de volta" e por parte dos que têm de se confrontar com o fato a partir de uma realidade que lhes é externa. Para os indígenas, os tempos passado, presente e futuro vão se interpenetrando na construção narrativa desde os episódios da historiografia até os dias de hoje, sendo essa uma parte fundamental do sentido e da possibilidade de eles se tornarem agentes políticos reconhecidos pelo Estado. As suas demandas, assim, são sempre imediatas e qualquer tempo parece excessivo porque muito tempo já se passou.

No entanto, para os agentes públicos que prestam serviços aos indígenas, o reconhecimento étnico inaugura uma nova etapa, quando eles são confrontados com as demandas políticas de grupos que lhes eram até então inexistentes. Acompanhando os Charrua "em tudo que é porta" ao longo do trabalho de campo, percebi que o reconhecimento vai sendo absorvido de gota em gota, às custas da insistência, da pressa e da agressividade, que tanto incômodo provoca nos agentes públicos. Diante do aparecimento de uma nova demanda - que só se apresenta como nova para eles, não para os indígenas -, a primeira reação é de resistência, seguindo-se tentativas e erros, como foram os casos relatados neste texto.

\section{Agradecimentos}

À Comunidade Charrua de Porto Alegre pelas contribuições para a realização desta pesquisa; ao Departamento de Antropologia da Universidade Federal do Rio Grande do Sul e ao Departamento de Antropologia da Johns Hopkins University, por possibilitarem o meu engajamento no projeto de escrita da etnografia e à CAPES pela concessão de bolsa de estágio sênior (Processo 5043 09-3).

\section{Referências}

ARRUTI, J. M. Etnogêneses indígenas. Disponível em: $<$ http://pib.socioambiental.org/pt/c/no-brasil-atual/ quem-sao/etnogeneses-indigenas $>$. Acesso em: 15 abr. 2011.

BIHEL, J. Vita: a zone of social abandonment. Berkeley: University of California Press, 2006.

BRASIL, Constituição da República Federativa do Brasil, 1988, Capítulo VIII - Dos Índios. Disponível em: <http://www.planalto.gov.br/ccivil_03/constituicao/ constitui\%C3\%A7ao.htm>. Acesso em: 15 abr. 2011.

BRUNER, E. Ethnography as narrative. In: TURNER, $\mathrm{V}$; BRUNER, E. The anthropology of experience. Urbana e Chicago: University of Illinois Press, 1986a. p. 139-158.
BRUNER, E. Experience and its expressions. In: TURNER, V; BRUNER, E. The anthropology of experience. Urbana e Chicago: University of Illinois Press, 1986b. p. 3-32. BUCHILLET, D. Bibliografia crítica da saúde indígena no Brasil. Quito: Ediciones Abya-Yala, 2007.

COUTINHO, L.; PAULIN, I.; MEDEIROS, J. A farra da antropologia oportunista. Revista Veja, Edição 2163, maio 2010. Disponível em: <http://veja.abril.com.br/050510/ farra-antropologia-oportunista-p-154.shtml>. Acesso em: 2 mar. 2011.

DAS, V. Critical events: an anthropological perspective on contemporary India. New Delhi: Oxford University Press, 1999. 
DAS, V. Life in words: violence and the descent into the ordinary. Berkeley, Los Angeles and London: University of California Press, 2007.

DAS, V. et al. (Org). Remaking a world: violence, social suffering and recovery. Berkeley, Los Angeles andLondon. University of California Press, 2001.

DAS, V. et al. (Org.). Violence and subjectivity. Berkeley, Los Angeles and London: University of California Press, 2000. DIÁRIO OFICIAL DE PORTO ALEGRE Ano XIII, Edição 3240, Decreto 15883. Porto Alegre, 31 de março de 2008.

ECKERT, C; ROCHA, A. L. C. Nos jogos de memória e as curvaturas do tempo. In:

Porto Alegre: Ed. UFRGS, 2005 O tempo e a cidade.

FASSIN, D. When bodies remember. Berkeley: University of California Press, 2007.

FRENCH, J. H. Mestizaje and law making in indigenous identity formation in northeastern Brazil: "After the conflict came the history". American Anthropologist, v. 106, n. 4, p. 663-674, 2004.

HALBWACHS, M. On colective memory. Chicago and London: The University of Chicago Press,1992.

KLEINMAN, A.; DAS, V.; LOCK, M. (Org) Social suffering. Berkeley, Los Angeles and London: University of California Press, 1997.

KLEINMAN, A; KLEINMAN, J. Suffering and its professional transformation: toward an ethnography of interpersonal experience. Culture, Medicine and Psychiatry, v.15, n.3, p. 275-301, 1991.

KLEINMAN, A; KLEINMAN, J. The appeal of experience the dismay of images cultural appropriations of suffering in our times. In: KLEINMAN, Arthur; DAS, Veena; LOCK, Margareth. Social suffering. Berkeley and Los Angeles: University of California Press, 1997.

LANGDON, E. Diversidade cultural e os desafios da política brasileira de saúde do índio. Saúde e Sociedade, São Paulo, v.16, n.2, p.7-12, 2007.

LANGDON, E.; DIEHL, E. Participação e autonomia nos espaços interculturais de saúde indígena: reflexões a partir do sul do Brasil. Saúde e Sociedade, São Paulo, v.16, n.2, p. 19-36, 2007.
LANGON, E.; GARNELO, L. Saúde dos povos indígenas: reflexões sobre antropologia participativa. Rio de Janeiro: Contracapa Livraria, 2004.

LEITE, S. Charrua: cada vez mais vivos. In: CONGRESSO DA SOCIEDADE DE ARQUEOLOGIA BRASILEIRA- REGIONAL SUL, 5., Tubarão, out. 2008. Trabalho não publicado.

LEITE, S. O povo Charrua em Porto Alegre: genealogia. Relatório de pesquisa. Porto Alegre, abr. 2010. Trabalho não publicado.

MINISTÉRIO DA JUSTIÇA. Fundação Nacional do Índio. Diretoria de Assuntos Fundiários. Ofício no 757 DAF /07, 28 de setembro de 2007 [para] SCHMIDT, Miriam. Comissão de Cidadania e Direitos Humanos, Assembleia Legislativa do Estado do Rio Grande do Sul, Porto Alegre. OIT BRASIL. Os direitos fundamentais dos povos indígenas e tribais. Disponível em: <http://www.socioambiental.org/ inst/esp/consulta_previa/?q=convencao-169-da-oit-nobrasil/a-convencao-169-da-oit>. Acesso em: 15 abr. 2011. OLIVEIRA, J. P. Uma etnologia dos "índios misturados"? Situação colonial, territorialização e fluxos culturais. Mana, v. 4, n. 1, p. 47-77, 1998.

PICERNO, J. E. El genocidio de la población Charrúa. Montevideo: Ediciones de la Bilioteca Nacional de Urugay, 2009. ROCHA, A. L. C.; ECKERT, C. Os jogos da memória. Ilha, Florianópolis, n. 1, p. 71-84, dez. 2000.

SILVA, S.B. Categorias sócio-cosmológico-identitárias indígenas recentes e processos de consolidação de novos sujeitos coletivos de direito: os Charrrua e os Xokleng no Rio Grande do Sul. In: FREITAS, A.; FAGUNDES, L. F. C.(Org). Povos indígenas na Bacia Hidrográfica do Lago Gauíba. Porto Alegre: Prefeitura de Porto Alegre, 2008.

SILVA. T. C. "Soldado é superior ao tempo": da ordem militar à experiência do corpo como lócus de resistência. Horizontes Antropológicos, Porto Alegre, PPGAS/UFRGS. v. 4, n.9, p. 119-143, 1998.

SILVA. T. C. Eventos críticos: sobreviventes, narrativas, testemunhos e silêncios. In: REUNIÃO BRASILEIRA DE ANTROPOLOGIA, 27., 2010, Belém. Anais... Disponível em: <http://www.iconecv.com.br/27rba/>. Acesso em: 10 abr. 2010. 


\title{
"El viaje de regreso": el reconocimiento étnico de indígenas en el sur de Brasil como un evento crítico
}

\section{Resumen}

El presente artículo se enfoca en la problemática del reconocimiento étnico de indígenas por parte del Estado. Sugiere que este proceso puede ser pensado como un evento crítico, en el sentido de que transforma percepciones, acciones y relaciones entre diferentes agentes involucrados en los procesos de territorialización, además de posibilitar la construcción de memorias que han de tejer discursos y narrativas específicas. A partir de una investigación etnográfica realizada junto a la comunidad Charrua de la Aldea Polidoro, en Porto Alegre (Brasil), abordo inicialmente la historiografía de los indios Charrua del Uruguay, que resalta fundamentalmente la extinción de la etnia, para contraponer después sus narrativas, que asumen la óptica de la supervivencia, condición de posibilidad para su reconocimiento en el Brasil actual. Posteriormente, presentaré situaciones y discursos que considero reveladores de la conflictiva relación de estos indígenas con algunos agentes públicos que se ven confrontados con la agenda y la agencia políticas de este "nuevo" pueblo. Finalmente, sugeriré que, en parte, esos conflictos estén relacionados con maneras diferentes de experienciar el tiempo. Para los indígenas, por un lado, la construcción narrativa que les da la posibilidad de reconocerse y ser reconocidos como tales implica la corporificación de la interpenetración de los tiempos pasado y presente y, en este sentido, su espera por la promoción de sus derechos constitucionales es contada desde un tiempo muy remoto. Por otro lado, para los agentes públicos, el reconocimiento étnico oficial es un punto específico en el presente, a partir del cual inician un lento y gradual proceso de reconocimiento de aquella condición de indígenas, reforzados por el "tiempo de la burocracia" en el cual están inmersos cotidianamente.

\section{"The return journey": the ethnic recognition of indigenous people in southern Brazil as a critical event}

\begin{abstract}
This article focuses on the ethnic recognition of indigenous groups by the State in Brazil and suggests that this may be thought of as a critical event in the sense that it promotes changes in perceptions, actions and relations between different actors involved in the processes of territorialization, in addition to allowing the construction of memories that weave specific discourses and narratives. Drawing on an ethnographic study carried out among the Charrua Community of the Polidoro Village in Porto Alegre (Brazil)., the first part of this paper is an introduction to the historiography of the Charrua Indians of Uruguay that highlights the group's genocide. To that I compare to the indigenous people's narratives that take on the perspective of survival, a condition of possibility for their recognition as indigenous in the present. After that, I introduce situations that I find revealing of their contentious relationship with some State agents who are faced with the political agenda and agency of this "new" indigenous people. Finally, I suggest that, in part, these conflicts are related to different ways of experiencing time. On the one hand, for the indigenous people, the narrative that gives them possibility to recognize themselves and be recognized as such implies the embodiment of an interpenetrated past and present time. Therefore, for those who record time since a distant past, the wait for the granting of their Constitutional rights by State agents seems always too long. On the other hand, for the public agents, State recognition happens at a specific point in the present, from which they start a slow and gradual processes of recognition of the indigenous people's situation, within the "time of the bureaucracy", in which they are immersed in their everyday.
\end{abstract}

Key words: critical event; construction of narratives; ethnic recognition; indigenous peoples; time.

Data de recebimento do artigo: 09/05/2011

Data de aprovação do artigo: 29/07/2011 